\title{
Review
}

Respiration

Published online: March 1, 2012

DOI: $\underline{10.1159 / 000335839}$

\section{The Upper Airway Resistance Syndrome}

\author{
J.L. Pépin ${ }^{a, b} \quad$ M. Guillot ${ }^{a, b} \quad$ R. Tamisier ${ }^{a, b} \quad$ P. Lévy ${ }^{a, b}$

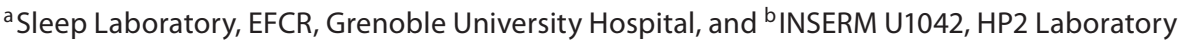 \\ (Hypoxia: Pathophysiology), Grenoble, France
}

\section{Key Words}

Sleep apnea $\cdot$ Hypopnea $\cdot$ Upper airway resistance $\cdot$

Diurnal sleepiness $\cdot$ Respiratory arousals $\cdot$ Cardiovascular

comorbidities

\begin{abstract}
Obstructive sleep apnea syndrome has been recognized as a major public health problem. Both its cardiovascular and metabolic comorbidities and symptoms motivate for an accurate diagnosis and appropriate treatment. The main stimulus associated with obstructive sleep apnea (OSA) and explaining deleterious consequences is intermittent hypoxia. The upper airway resistance syndrome (UARS) has been described based on the hypothesis that snoring and repetitive occurrence of respiratory effort-related arousals (RERAs) but not oxygen desaturation might produce a significant disease with symptoms, altered quality of life and cardiovascular morbidity. Diurnal sleepiness remains the main diagnostic criteria, which is often confounded with tiredness in women. UARS patients may also report insomnia and symptoms that closely resemble those of the functional somatic syndromes. Currently, the International Classification of Sleep Disorders does not individualize UARS as a specific entity and reports UARS patients as a subgroup of OSA. However, RERAs are described as unambiguous abnormal respi-
\end{abstract}

ratory events occurring during sleep and requiring a specific scoring. In this review, the authors attempt to describe the specific characteristics of UARS that are relevant for both clinicians and researchers.

Copyright $\odot 2012$ S. Karger AG, Basel

\section{Introduction}

Since the obstructive sleep apnea syndrome (OSAS) has been recognized as a major public health problem [1, 2], many efforts have been made to define and understand this syndrome [3]. Breathing abnormalities during sleep are not limited to patients exhibiting typical obstructive apnea but include a continuum of events from simple snoring to OSAS that constitute a group of diseases named sleep breathing disorders. The upper airway resistance syndrome (UARS) was initially reported by Guilleminault et al. [4] in 1993. This particular syndrome has been described based on the hypothesis that repetitive increases in respiratory efforts that are inducing

J.L. Pépin and M. Guillot contributed equally to this work. This paper has been presented at the Swiss Respiratory Society meeting, Interlaken, May 4-6, 2011.

\section{KARGER}

Fax +4161306 1234

E-Mail karger@karger.ch

www.karger.com
(C) 2012 S. Karger AG, Basel

0025-7931/12/0836-0559\$38.00/0

Accessible online at:

www.karger.com/res
Prof. Jean-Louis Pépin

EFCR, Unité Sommeil et Respiration

CHU de Grenoble, BP 217 X

FR-38043 Grenoble (France)

Tel. +33 47676 5516, E-Mail jpepin@ @hu-grenoble.fr 
arousals might produce a significant disease leading to daytime sleepiness and functional symptoms and is associated with cardiovascular and cognitive morbidities. The definitions of sleep breathing disorders published by the American Academy of Sleep Medicine (AASM) Task Force [3] in 1999 did not include UARS as a syndrome but precisely described respiratory effort-related arousals (RERAs). There is still a debate about the true existence of UARS as a specific disease and regarding cardiovascular consequences that might be attributed to RERAs [5]. The International Classification of Sleep Disorders (ICSD II), published in 2005, is overall in accordance with the AASM Task Force [6] report published in 1999. Events associating an absence of oxygen desaturation despite a clear drop in inspiratory flow, increased respiratory effort and a brief change in sleep state or arousal are defined as RERAs. The UARS is a proposed diagnostic classification for patients who exhibit RERAs but do not also have events that would meet definitions for apneas and hypopneas. RERAs are presumed to have a similar pathophysiology to obstructive apneas and hypopneas (upper airway obstruction) and are believed to be as much of a risk factor for symptoms of unrefreshing sleep, daytime somnolence, and fatigue as frank apnea or hypopnea. Therefore, ICSD II recommends that UARS should be included as part of OSA and not considered as a separate entity [6].

\section{Definition}

UARS is defined by the occurrence of excessive daytime sleepiness unexplained by another cause and associated with more than $50 \%$ of respiratory events that are nonapneic and nonhypopneic (i.e. RERAs). RERAs are characterized by a progressive increase in respiratory effort. This may be assessed by direct measurement of esophageal pressure or by another marker of respiratory effort such as the changes in pulse transit time (fig. 2). RERAs may induce both cortical and autonomic arousals [7] and potentially lead to cardiovascular activation. Respiratory flow, when using nasal cannula or a pneumotachograph, exhibits only qualitative change named inspiratory flow limitation. This is of interest since inspiratory flow limitation results from the progressive increase in upper airway (UA) resistance [8]. Flow limitation is a physiologic phenomenon that can be identified from the nasal pressure signal thus allowing noninvasive detection of RERAs [9]. The time sequence of these obstructive respiratory events is close to what occurs with apneas and hypopneas, but the duration may be longer. This should be distinguished from episodes of sustained stable flow limitation occurring during slow wave sleep. This late flow-limited aspect does not lead to repeated arousals and thus differs from RERAs.

To qualify as an individual disease, UARS should meet the following criteria:

- first, to exhibit specific clinical and polysomnographic diagnostic criteria;

- second, these specific criteria should not be found in the general population;

- third, a direct relationship should be found between this syndrome and a specific morbidity.

\section{UARS Prevalence and Specific Clinical Characteristics}

Snoring is reported to be present in $41 \%$ of the general population aged between 26 and 50 years. In this cluster of the population, $15 \%$ exhibit an apnea-hypopnea index of more than 15 events per hours of sleep [2]. Snoring is reported in $71 \%$ of men and $11 \%$ of women exhibiting UARS [10]. In a retrospective review of all polysomnographies performed in an academic military sleep disorder center during the year 2000, the prevalence of UARS was $8.4 \%$ [11]. The true prevalence of UARS in the general population is unknown and pure UARS is rather rare in clinical practice. UARS patients were significantly younger, less overweight and had lower weight gain during the past 5 years compared to OSA patients [12]. The femaleto-male ratio seems to be highest in the UARS group.

Diurnal sleepiness remains the main diagnostic criteria, which is often confounded with tiredness in women. Twenty percent of UARS patients may report insomnia. All other OSAS clinical criteria may apply to UARS such as nocturia, nocturnal awakening, sleep inefficiency, and cognitive impairment. Headaches, vasomotor rhinitis, and irritable bowel syndrome have also been described as more frequently associated with UARS $[12,13]$. The symptoms of UARS, then, closely resemble those of the functional somatic syndromes. Several authors argue about the fact that these symptoms are not specific enough compared to OSAS and are quite similar to those reported during chronic asthenia [14]. Psychological complaints are also reported, such as difficulty in concentrating and depressive mood [12]. Patients with UARS are most impaired in terms of their daily functioning and perception of sleep quality. Accordingly, these patients seem to consume more hypnotics, antidepressants or stimulants if they are not treated. Owing to the lack of 
Fig. 1. Typical craniofacial features in UARS patients. Representative patients suffering from UARS with classical craniofacial abnormalities, i.e. long face syndrome with a short and narrow chin and with the mandible in the back position (a, b). c During clinical examination, dental overjet and ogival hard palate are typical features of UARS [modified from 51].
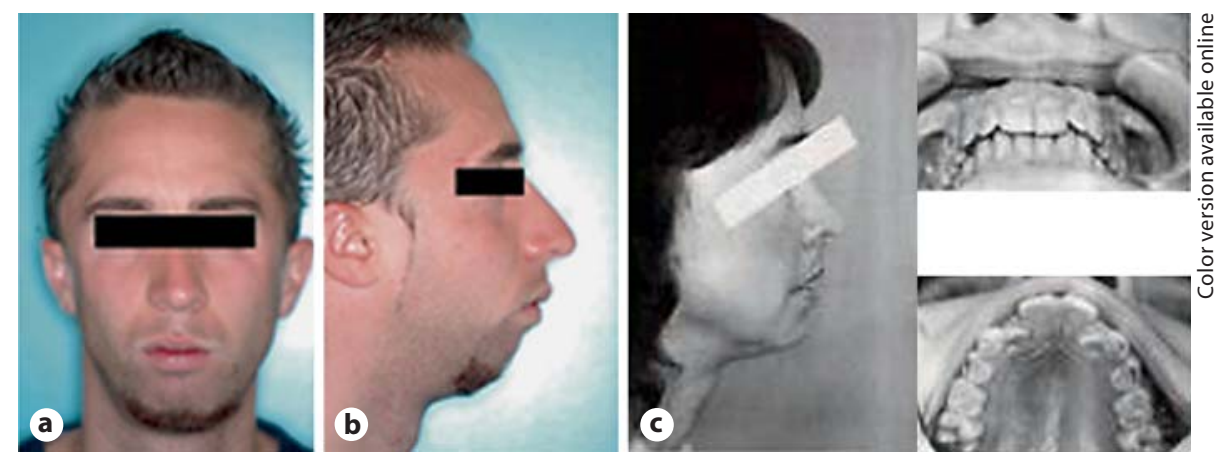

specificity of the reported symptoms, the question is to know whether these complaints are corroborated by objective measures. When measuring the tendency to fall asleep by multiple sleep latency tests in 137 UARS, Gold et al. [15] reported that UARS patients frequently complained about sleepiness but were objectively less sleepy compared to mild-to-moderate and severe OSAS patients. Powers and Frey [16] measured maintenance wakefulness tests in 19 UARS patients and found that $33 \%$ of them exhibited a mean sleep latency below $19.4 \mathrm{~min}$ (i.e. $<2$ SD below normal values). Psychomotor performances assessed by measurements of reaction time have been compared in 47 UARS matched by gender and age with 47 OSAS patients [17]. Patients with UARS presented worse psychomotor performance on most test metrics than patients with OSAS. These results may suggest that patients with UARS may also present an increased risk of motor vehicle crashes as previously demonstrated in OSAS patients [17].

Regarding clinical examination, some craniofacial characteristics were reported as being specific to UARS [10]. These patients exhibit the classical long face syndrome with a short and narrow chin and reduced mouth opening (fig. 1). There is classically a 'click' and a subluxation when opening the temporo-mandibular articulation, which may be evidenced by palpation. The mandible is in the back position and the palate is high and narrow. Finally, Guilleminault et al. [18] have described a lowresting arterial blood pressure or orthostatic intolerance as occurring in one fifth of subjects with UARS.

UARS may also need to be considered in severely obese young patients [19]. These authors reported a high prevalence of UARS (about 15 to $20 \%$ based on polysomnographic criteria). We found similar results in a population of severely obese patients who were referred for consultation without sleep complaints [Tamisier, unpubl. data]. The physiopathology of UARS in these patients may de- serve some discussion as the repetitive RERAs they experienced might not only be a consequence of UA collapse but may reflect the increase in respiratory work due to reduced thoracoabdominal compliance. However, polysomnographic criteria are close to those used in young lean UARS patients.

Regarding the evolution of the disease, the severity of UARS remains stable over time [20]. The progression from UARS to OSAS seems to be related to an increase in the body mass index [21].

\section{Particularities of Polysomnographic Patterns and Diagnosis}

RERAs and arousal detection are the key elements during sleep monitoring (fig. 2). RERAs correspond to a sequence of breaths characterized by increasing respiratory effort leading to an arousal from sleep, but which does not meet criteria for an apnea or hypopnea in terms of flow reduction. These events must fulfill both of the following criteria: (1) a pattern of progressively more negative esophageal pressure, terminated by a sudden change in pressure to a less negative level and an arousal, and (2) the event lasts $10 \mathrm{~s}$ or longer. The number of events may be underestimated when tools used during this monitoring are not appropriate. By definition, detection of RERAs is based on accurate flow measurement using the nasal cannula or a pneumotachograph [9] and respiratory effort measurement using either oesophageal pressure or pulse transit time $[3,22,23]$. By using a nasal thermocouple to detect flow a shift between hypopnea to RERA will occur and an authentic OSAS will be misdiagnosed to a UARS. This has been described by Montserrat and Badia [24] as the 'thermistance syndrome'. We investigated subjects presenting with sleep-disordered breathing and very little oxygen desaturations, thus being 
Fig. 2. Representative pattern of RERAs during a sleep study. The figure depicts the recurrence of RERAs with a progressive flow limitation aspect on nasal cannula which corresponds to an increase in respiratory effort (both esophageal pressure and pulse transit time). The consequences of these events are both sleep fragmentation (frank autonomic arousal on the first and third events) and arterial blood pressure rises.

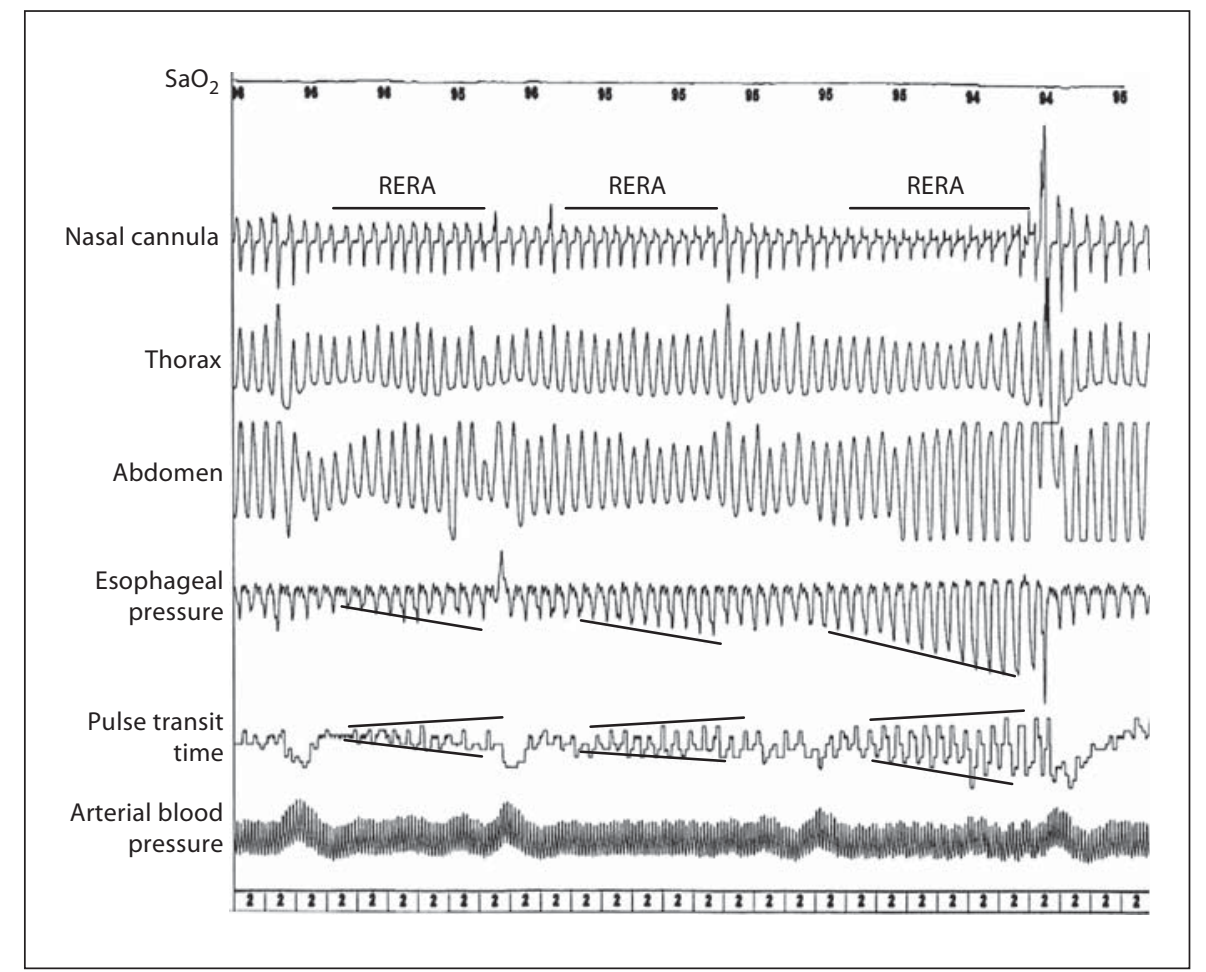

either mild OSAS or UARS, using the reference tools (pneumothachograph and esophageal pressure). They exhibited mainly hypopneas but we found only about $5 \%$ of true RERAs [7]. RERAs must be considered as specific respiratory events expressed by patients depending on their UA collapsibility. To this extent, it is logical to include RERAs in the respiratory disturbance index.

The detection of RERAs requires a reliable measure for respiratory efforts. In adults, pharyngeal and/or esophageal pressure [25] and variation of pulse transit time are usually reliable enough to be used in this way $[22,23,26]$. An optimal evaluation of inspiratory flow limitation may be used to detect RERAs [9]. However, two limitations need to be mentioned. First, inspiratory flow limitation is an indirect consequence of respiratory effort and may be less accurate in REM sleep. Second, reliability of analysis requires a good flow signal quality which may depend upon both hardware and software. Inspiratory flattening of time derivatives of respiratoryinductive plethysmography volume signals and marked ribcage/abdominal asynchrony may also allow differentiating UA resistance episodes from simple snoring [27, 28]. A computer-assisted analysis of respiratory-inductive plethysmography has been proposed to improve the detection of such events [29].
Sleep fragmentation may be quantified by direct arousal detection using electroencephalographic measures following the specific American Sleep Disorders Association (ASDA) criteria [30] or using autonomic tools like pulse transit time [31].

\section{UARS Pathophysiology}

The pharyngeal collapse depends on the balance between collapsible factors like UA narrowing [32], pharyngeal collapsibility and protective factors like UA-dilating muscle activity and the protective pharyngeal reflexes [33]. Patients with UARS are less obese than OSA patients and exhibit typical craniofacial abnormalities (see above) leading to a size reduction of the pharynx. Obstructive respiratory-event severity is not related to differences in respiratory effort magnitude as assessed by esophageal pressure crescendo, but rather to a different UA collapsibility [7]. Depending upon UA collapsibility and UA protective mechanisms, a given patient exhibits a variable combination of abnormalities among the full spectrum of obstructive respiratory events. Collapsibility can be anticipated by measuring critical pressure during sleep. Critical pressures in UARS are in intermediate values be- 


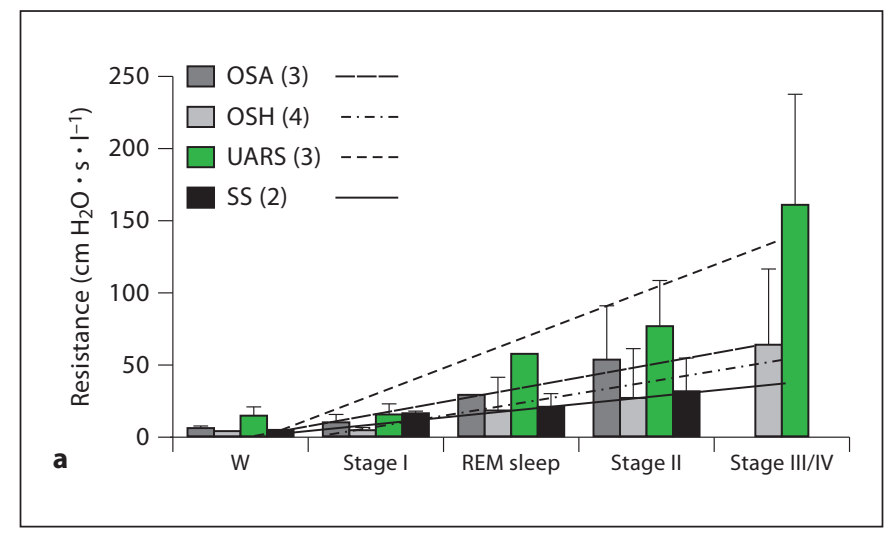

Fig. 3. Specific pathophysiology of UARS [modified from 8]. a When measuring UA resistance, UARS is able to maintain higher levels of UA resistances in any sleep stage compared to OSAS. $\mathrm{OSH}=$ Obstructive sleep hypopnea; SS = simple snorers. $\mathbf{b}$ Relative proportion of apnea-hypopnoea (AHI) and high-resistance episodes (RERA index: HRI) indices in 3 groups of patients with UARS, and moderate and severe OSAS. In these subgroups of pa-

tween OSAS and normals: $-4.0 \pm 2.1,-1.6 \pm 2.6$ and $-15.4 \pm 6.1 \mathrm{~cm} \mathrm{H}_{2} \mathrm{O}$, respectively [34, 35]. Using negative expiratory pressure, we also confirmed a reduced UA collapsibility in UARS when compared to OSAS [36]. As a consequence, when measuring UA resistances, UARS patients are able to maintain higher levels of UA resistance in any sleep stage compared to OSAS patients [8] (fig. 3). This intermediate UA collapsibility is associated with flow limitation or UA resistance events instead of apneas for the same level of respiratory effort in OSAS exhibiting severe UA collapsibility (fig. 3) [7,37]. The ability of UARS patients to maintain UA opening at high levels of UA resistance is partly explained by more preserved protective reflexes of the pharynx. Two studies have demonstrated that UARS subjects exhibit UA sensitivity close to normals $[38,39]$. As UA sensitivity is not impaired in UARS, these patients are able to activate the protective reflexes with the consequence of very high levels of dilating muscle activity explaining the facility to counteract high levels of UA resistances.

\section{UARS-Associated Cardiovascular Comorbidities}

Obesity and intermittent hypoxia play a major role in explaining cardiovascular and metabolic consequences associated with sleep apnea [40]. UARS patients are less obese than OSAS patients and by definition do not reveal

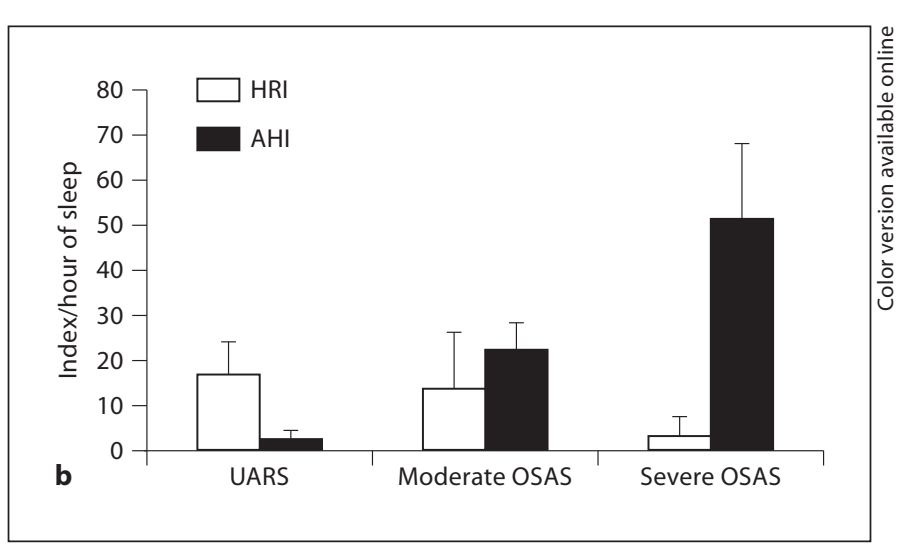

tients, the absolute number of respiratory events did not differ significantly. However, the amount of high collapsibility events (i.e. apnea and hypopnea) and low collapsibility events (i.e. RERA) depend upon the sleep disorder exhibited by the patient. Patients with UARS exhibit predominantly RERA and hypopnea, while severe OSAS patients exhibit mostly apneas in relation to their UA collapsibility status. $\mathrm{W}=$ Wake.

severe oxygen desaturation during sleep. The remaining mechanisms that might link UARS to cardiovascular and metabolic consequences are snoring, increased respiratory efforts throughout the night and sleep fragmentation.

Recent studies have underlined the potential role of snoring per se in the development of carotid atherosclerosis. Lee et al. [41] reported data in an observational cohort of 101 snorers and non-snorers with mild nonhypoxic obstructive sleep apnea hypopnea syndrome. Heavy snoring ( $>50 \%$ night snoring), diagnosed on PSG, was an independent factor for carotid atherosclerosis. This factor was a stronger predictor for carotid atherosclerosis than age, sex, smoking history, or hypertension. Convincingly, the prevalence of carotid atherosclerosis increased progressively according to the severity of snoring. The mechanism for the association is supposed to be purely mechanical, i.e. snoring vibrations may be transmitted through the surrounding tissues to the carotid artery wall, inducing endothelial damage and finally leading to carotid atherosclerosis. Carotid bifurcation is effectively the major site of carotid artery atherosclerotic plaques and is in close proximity to the hypopharyngeal wall. In the same population, femoral atherosclerosis was not observed whatever the snoring severity, which suggests that snoring is acting only mechanically at the carotid level. Even more recently, the role of pericarotid tissue vibration as able to induce carotid artery endothe- 
Fig. 4. UA resistance episodes are associated with blood pressure fluctuations and rises in $\mathrm{CO}_{2}$. UA resistance episodes are easy to reproduce by using suboptimal CPAP in CPAP-treated OSAS patients. It has been demonstrated in this situation that long-lasting flow limitation episodes induce not only acute changes in blood pressure but also a small increase in Pet$\mathrm{CO}_{2}$ [modified from 44].

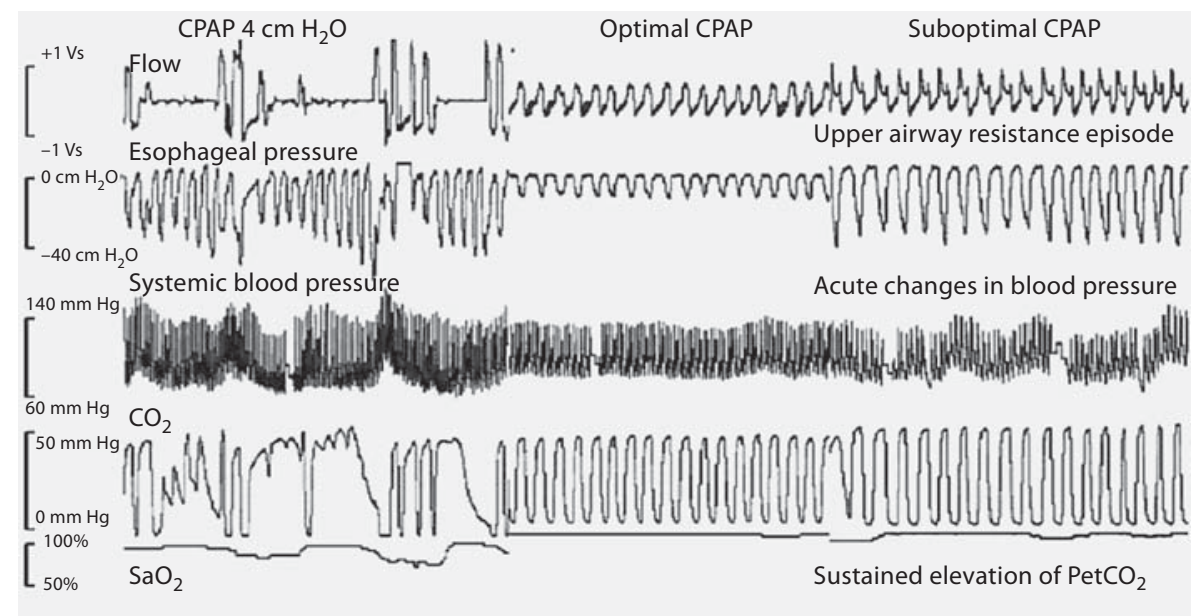

lial dysfunction and structural changes has been confirmed by the same group of authors in an animal model [42].

In UARS, the second key mechanism underlying cardiovascular consequences is the occurrence of repetitive micro-arousals ending the RERA episodes. Guilleminault et al. [43] firstly described repetitive increases in blood pressure as a result of airway resistance episodes during sleep. As depicted in figure 2, every micro-arousal is accompanied by an abrupt surge in blood pressure. UA resistance episodes without desaturation are easy to reproduce using suboptimal continuous positive airway pressure (CPAP) in CPAP-treated OSAS patients. Using this experimental setting, it has been demonstrated that longlasting flow limitation episodes induce not only acute changes in blood pressure but also a small increase in $\mathrm{PetCO}_{2}$ [44] (fig. 4). It is well established that any increase in $\mathrm{CO}_{2}$ also stimulates the activity of the sympathetic nervous system. Sleep fragmentation by arousing normal healthy humans from sleep over 2 nights (30-40 times/h) was also able to cause a $20 \%$ decrease in the insulin sensitivity [45]. Consequently, UARS-induced sleep fragmentation and prolonged episodes of inspiratory flow limitation might lead to a chronic increase in sympathetic outflow that could explain the secondary occurrence of hypertension, and cardiovascular and metabolic consequences. However, few data actually exist to relate UARS to cardiovascular consequences [ $43,46,47]$. Lofaso et al. [48] reported that nonapneic-nonhypopneic obstructive events are followed by arterial systemic pressure increases whose magnitude varies with the grade of the arousal. Accordingly, Lofaso et al. [49] studied 105 mid- dle-aged nonapneic snorers and found that systemic hypertension was significantly higher in the sleep-fragmented group (i.e. UARS). Orthostatic hypotension has also been associated with UARS [18] but large epidemiological studies focusing on the cardiovascular consequences of UARS are lacking. Overall, even though there are some mechanistic hypotheses, the degree of evidence to support a significant cardiovascular morbidity in UARS is very limited.

\section{UARS Treatment Strategy}

Therapeutic data are few and no UARS cohorts with long-term treatment and follow-up are available. CPAP has been used to evaluate the potential improvements that can be obtained regarding functional outcomes [4]. Compliance to treatment is limited in the subgroup of UARS. However, since several studies have demonstrated CPAP efficacy in mild OSAS, CPAP should also be considered as an appropriate treatment for UARS.

As many patients exhibit maxillofacial abnormality, surgery appears a logical indication. To our knowledge, no surgical study has specifically targeted UARS patients. Furthermore, no evaluation exists for laser-assisted or radiofrequency surgery in this specific indication.

As these patients are lean and frequently present with retrognathia, the use of mandibular advancement devices is a commonsense decision, with the advantage of being reversible where surgery is not [50]. However, a large study in the specific indication of UARS with appropriate outcome evaluation is required. 


\section{Conclusion}

UARS is a relatively rare condition. Patients are presenting with excessive daytime sleepiness and functional somatic syndromes. The pathophysiology is specific with a relatively low collapsibility of the UA and preserved pharyngeal reflexes. Diagnosis during sleep studies requires the use of appropriate tools for measuring respiratory effort (i.e. esophageal pressure or pulse transit time). There is a need for more clinical and translational research to determine whether sleep fragmentation alone can contribute to the development of cardiovascular and metabolic consequences [33]. UARS may persist without further evolution towards apneic events except in the case of weight gain. Oral appliances represent the best therapeutic option when feasible. Unfortunately, the studies of UARS patients have been largely observational. No evidence from randomized studies is available that would underpin a causal relationship between the physiologic observations made in patients with the syndrome, specific symptoms and cardiovascular consequences. The treatment strategy is still an expert opinion.

\section{References}

$>1$ Phillipson EA: Sleep apnea - a major public $>_{12}$ Stoohs RA, Knaack L, Blum HC, Janicki J, health problem. N Engl J Med 1993;328: 1271-1273.

-2 Strohl KP, Redline S: Recognition of obstructive sleep apnea. Am J Respir Crit Care Med 1996;154:279-289.

$>3$ Sleep-related breathing disorders in adults: recommendations for syndrome definition and measurement techniques in clinical research. The report of an American Academy of Sleep Medicine Task Force. Sleep 1999;22: 667-689.

-4 Guilleminault C, Stoohs R, Clerk A, Cetel M, Maistros P: A cause of excessive daytime sleepiness. The upper airway resistance syndrome. Chest 1993;104:781-787.

$\checkmark 5$ Guilleminault C, Léger D: Le syndrome des voies aériennes supérieures: pertinence clinique et physiopathologique. Rev Mal Respir 2005;22:27-30.

6 International Classification of Sleep Disorders: Diagnostic and Coding Manual, ed 2. Westchester, American Academy of Sleep Medicine, 2005.

$>7$ Cracowski C, Pepin JL, Wuyam B, Levy P: Characterization of obstructive nonapneic respiratory events in moderate sleep apnea syndrome. Am J Respir Crit Care Med 2001; 164:944-948

8 Tamisier R, Pepin JL, Wuyam B, Smith R, Argod J, Levy P: Characterization of pharyngeal resistance during sleep in a spectrum of sleep-disordered breathing. J Appl Physiol 2000;89:120-130.

$>9$ Ayappa I, Norman RG, Krieger AC, Rosen A, O’Malley RL, Rapoport DM: Non-invasive detection of respiratory effort-related arousals (RERAs) by a nasal cannula/pressure transducer system. Sleep 2000;23:763-771.

10 Guilleminault C, Black JE, Palombini L: High (or abnormal) upper airway resistance (in French). Rev Mal Respir 1999;16:173-180.

$>11$ Kristo DA, Lettieri CJ, Andrada T, Taylor Y, Eliasson AH: Silent upper airway resistance syndrome: prevalence in a mixed military population. Chest 2005;127:1654-1657. Hohenhorst W: Differences in clinical features of upper airway resistance syndrome, primary snoring, and obstructive sleep apnea/hypopnea syndrome. Sleep Med 2008;9: 121-128.

13 Gold AR, Dipalo F, Gold MS, O’Hearn D: The symptoms and signs of upper airway resistance syndrome: a link to the functional somatic syndromes. Chest 2003;123:87-95.

14 Douglas NJ: Upper airway resistance syndrome is not a distinct syndrome. Am J Respir Crit Care Med 2000;161:1413-1416.

15 Gold AR, Gold MS, Harris KW, Espeleta VJ, Amin MM, Broderick JE: Hypersomnolence, insomnia and the pathophysiology of upper airway resistance syndrome. Sleep Med 2008;9:675-683.

16 Powers CR, Frey WC: Maintenance of wakefulness test in military personnel with upper airway resistance syndrome and mild to moderate obstructive sleep apnea. Sleep Breath 2009;13:253-258.

$\checkmark 17$ Stoohs RA, Philip P, Andries D, Finlayson EV, Guilleminault C: Reaction time performance in upper airway resistance syndrome versus obstructive sleep apnea syndrome. Sleep Med 2009;10:1000-1004.

$>18$ Guilleminault C, Faul JL, Stoohs R: Sleepdisordered breathing and hypotension. Am J Respir Crit Care Med 2001;164:1242-1247.

19 Frey WC, Pilcher J: Obstructive sleep-related breathing disorders in patients evaluated for bariatric surgery. Obes Surg 2003;13:676683.

20 Guilleminault C, Kirisoglu C, Poyares D, Palombini L, Leger D, Farid-Moayer M, Ohayon MM: Upper airway resistance syndrome: a long-term outcome study. J Psychiatr Res 2006;40:273-279.

21 Jonczak L, Plywaczewski R, Sliwinski P, Bednarek M, Gorecka D, Zielinski J: Evolution of upper airway resistance syndrome. J Sleep Res 2009; 18:337-341.

22 Argod J, Pepin JL, Levy P: Differentiating obstructive and central sleep respiratory events through pulse transit time. Am J Respir Crit Care Med 1998;158:1778-1783.

23 Argod J, Pepin JL, Smith RP, Levy P: Comparison of esophageal pressure with pulse transit time as a measure of respiratory effort for scoring obstructive nonapneic respiratory events. Am J Respir Crit Care Med 2000; 162:87-93.

24 Montserrat JM, Badia JR: Upper airway resistance syndrome. Sleep Med Rev 1999;3: $5-21$.

25 Guilleminault C, Poyares D, Palombini L, Koester U, Pelin Z, Black J: Variability of respiratory effort in relation to sleep stages in normal controls and upper airway resistance syndrome patients. Sleep Med 2001;2:397405.

-26 Poyares D, Guilleminault C, Rosa A, Ohayon M, Koester U: Arousal, EEG spectral power and pulse transit time in UARS and mild OSAS subjects. Clin Neurophysiol 2002;113: 1598-1606.

27 Bloch KE, Li Y, Sackner MA, Russi EW: Breathing pattern during sleep disruptive snoring. Eur Respir J 1997;10:576-586.

28 Brullmann G, Fritsch K, Thurnheer R, Bloch KE: Respiratory monitoring by inductive plethysmography in unrestrained subjects using position sensor-adjusted calibration. Respiration 2010;79:112-120.

29 Kaplan V, Zhang JN, Russi EW, Bloch KE: Detection of inspiratory flow limitation during sleep by computer assisted respiratory inductive plethysmography. Eur Respir J 2000;15:570-578.

30 EEG arousals: scoring rules and examples: a preliminary report from the Sleep Disorders Atlas Task Force of the American Sleep Disorders Association. Sleep 1992;15:173184.

31 Pitson DJ, Stradling JR: Autonomic markers of arousal during sleep in patients undergoing investigation for obstructive sleep apnoea, their relationship to EEG arousals, respiratory events and subjective sleepiness. J Sleep Res 1998;7:53-59. 
-32 Li Y, Ye J, Li T, Lin N, Wang Z, Liang C, Sperry A, Han D: Anatomic predictors of retropalatal mechanical loads in patients with obstructive sleep apnea. Respiration 2011;82: 246-253.

33 Dempsey JA, Veasey SC, Morgan BJ, O'Donnell CP: Pathophysiology of sleep apnea. Physiol Rev 2010;90:47-112.

34 Gleadhill IC, Schwartz AR, Schubert N, Wise RA, Permutt S, Smith PL: Upper airway collapsibility in snorers and in patients with obstructive hypopnea and apnea. Am Rev Respir Dis 1991;143:1300-1303.

35 Gold AR, Marcus CL, Dipalo F, Gold MS: Upper airway collapsibility during sleep in upper airway resistance syndrome. Chest 2002;121:1531-1540.

- 36 Tamisier R, Wuyam B, Nicolle I, Pepin JL, Orliaguet O, Perrin CP, Levy P: Awake flow limitation with negative expiratory pressure in sleep disordered breathing. Sleep Med 2005;6:205-213.

37 Loube DI, Andrada TF: Comparison of respiratory polysomnographic parameters in matched cohorts of upper airway resistance and obstructive sleep apnea syndrome patients. Chest 1999;115:1519-1524.

38 Dematteis M, Levy P, Pepin JL: A simple procedure for measuring pharyngeal sensitivity: a contribution to the diagnosis of sleep apnoea. Thorax 2005;60:418-426.
39 Guilleminault C, Li K, Chen NH, Poyares D: Two-point palatal discrimination in patients with upper airway resistance syndrome, obstructive sleep apnea syndrome, and normal control subjects. Chest 2002;122:866-870.

40 Chung S, Yoon IY, Lee CH, Kim JW: The association of nocturnal hypoxemia with arterial stiffness and endothelial dysfunction in male patients with obstructive sleep apnea syndrome. Respiration 2010;79:363-369.

41 Lee SA, Amis TC, Byth K, Larcos G, Kairaitis K, Robinson TD, Wheatley JR: Heavy snoring as a cause of carotid artery atherosclerosis. Sleep 2008;31:1207-1213.

42 Cho JG, Witting PK, Verma M, Wu BJ, Shanu A, Kairaitis K, Amis TC, Wheatley JR: Tissue vibration induces carotid artery endothelial dysfunction: a mechanism linking snoring and carotid atherosclerosis? Sleep 2011;34: 751-757.

43 Guilleminault C, Stoohs R, Shiomi T, Kushida C, Schnittger I: Upper airway resistance syndrome, nocturnal blood pressure monitoring, and borderline hypertension. Chest 1996;109:901-908.
44 Calero G, Farre R, Ballester E, Hernandez L, Daniel N, Montserrat Canal JM: Physiological consequences of prolonged periods of flow limitation in patients with sleep apnea hypopnea syndrome. Respir Med 2006;100: 813-817.

45 Stamatakis KA, Punjabi NM: Effects of sleep fragmentation on glucose metabolism in normal subjects. Chest 2010;137:95-101.

46 Exar EN, Collop NA: The upper airway resistance syndrome. Chest 1999;115:1127-1139.

47 Stradling JR, Barbour C, Glennon J, Langford BA, Crosby JH: Which aspects of breathing during sleep influence the overnight fall of blood pressure in a community population? Thorax 2000;55:393-398.

48 Lofaso F, Goldenberg F, d'Ortho MP, Coste A, Harf A: Arterial blood pressure response to transient arousals from NREM sleep in nonapneic snorers with sleep fragmentation. Chest 1998;113:985-991.

49 Lofaso F, Coste A, Gilain L, Harf A, Guilleminault C, Goldenberg F: Sleep fragmentation as a risk factor for hypertension in middle-aged nonapneic snorers. Chest 1996;109: 896-900.

50 Yoshida K: Oral device therapy for the upper airway resistance syndrome patient. J Prosthet Dent 2002;87:427-430. 